\title{
Sulfolobus hakonensis sp. nov., a Novel Species of Acidothermophilic Archaeon
}

\author{
SHINNOSUKE TAKAYANAGI,${ }^{1 *}$ HIROKO KAWASAKI,${ }^{2}$ KENJI SUGIMORI,${ }^{1}$ TAKESHI YAMADA, ${ }^{1}$ \\ AKIHIKO SUGAI, ${ }^{3}$ TOSHIHIRO ITO,${ }^{3}$ KAZUHIDE YAMASATO,${ }^{2} \dagger$ AND MASAKI SHIODA ${ }^{4}$ \\ Department of Biology, Toho University School of Medicine, Ota-ku, Tokyo 143, ${ }^{1}$ Institute of Molecular and Cellular \\ Biosciences, $\neq$ The University of Tokyo, Bunkyo-ku, Tokyo $113,^{2}$ Division of Chemistry, College of Liberal Arts and \\ Sciences, Kitasato University, Sagamihara, Kanagawa $228,{ }^{3}$ and Department of Biological Science, Faculty of Science, \\ Kumamoto University, Kurokami, Kumamoto $860,{ }^{4}$ Japan
}

\begin{abstract}
We characterized a microbial strain that was isolated from a hot spring at a geothermal area in Hakone, Japan. This isolate, whose lobed-shaped cells were about $1.0 \mu \mathrm{m}$ in diameter, was a facultative chemolithoautotroph that required aerobic conditions for growth. The optimum $\mathrm{pH}$ was 3.0 (pH range, 1.0 to 4.0), and the optimum temperature was $70^{\circ} \mathrm{C}$ (temperature range, 50 to $80^{\circ} \mathrm{C}$ ). Lithotrophically, this strain grew on elemental sulfur and reduced sulfur compounds. The $G+C$ content of the genomic DNA was 38.4 mol\%. This organism contained calditoglycerocaldarchaeol, which is characteristic of members of the Sulfolobaceae. The levels of 16S rRNA sequence similarity between the new isolate and Sulfolobus acidocaldarius, Sulfolobus solfataricus, and Sulfolobus shibatae were less than $89.8 \%$. Unlike $S$. acidocaldarius, $S$. solfataricus, and $S$. shibatae, the new isolate utilized sugars and amino acids poorly as sole carbon sources, and the levels of DNA-DNA hybridization between the new isolate and these Sulfolobus species were very low. Phenotypically, the new isolate was also distinct from the obligately lithotrophic organism Sulfolobus metallicus. We concluded that the new organism belongs to a new Sulfolobus species, for which we propose the name Sulfolobus hakonensis.
\end{abstract}

Extreme acidothermophiles are found in acidic hot springs, water holes, and mud holes that contain elemental sulfur $(1,2$, 5). The genus Sulfolobus, which belongs to the family Sulfolobaecae, contains microorganisms that live in such habitats, and this genus was the first acidothermophilic genus of archaea (previously archaebacteria) described (2, 25, 29, 31). Members of this genus grow aerobically at low $\mathrm{pH}$ values and high temperatures in the presence of elemental sulfur $(2,9,11,31)$. Four Sulfolobus species have been identified and characterized previously $(2,9,11,31)$. The assignment of species to the genus Sulfolobus has been questioned recently $(16,30)$. Sulfolobus acidocaldarius and Sulfolobus solfataricus, which are widely used in laboratory experiments, were isolated from hot springs at Yellowstone National Park in the United States and at Pisciarelli, Italy, respectively, and apparently are distributed worldwide $(2,31)$. As exact characterization of these taxa and taxonomic comparisons between Sulfolobus strains found in different places have not been performed, the possibility that the genus Sulfolobus includes many more species requires attention.

In this paper we describe a new species of the genus Sulfolobus that was isolated from an acidic hot spring at a geothermal area in Hakone, Japan. This species can be distinguished from the previously described Sulfolobus species by nutritional, DNA homology, and 16S rRNA sequences characteristics.

\section{MATERIALS AND METHODS}

Microbial strains. $S$. acidocaldarius DSM $639^{\mathrm{T}}(\mathrm{T}=$ type strain) and $S$ solfataricus DSM $1616^{\mathrm{T}}$ were obtained from the Deutsche Sammlung von Mikroorganismen und Zellkulturen, Braunschweig, Germany. Escherichia coli IAM

\footnotetext{
* Corresponding author.

$\dagger$ Present address: The Culture Collection Center, Tokyo University of Agriculture, Setagaya-ku, Tokyo 156, Japan.

$\ddagger$ Formerly Institute of Applied Microbiology.
}

1264 was obtained from the IAM Culture Collection, Institute of Molecular and Cellular Biosciences, The University of Tokyo.

Microbial growth and growth media. Our new isolate and the type strains of $S$. acidocaldarius and $S$. solfataricus were cultivated in Allen's medium, as modified by Brock et al. (2) (modified Allen's medium) under aerobic conditions at $70^{\circ} \mathrm{C}$. Modified Allen's medium contained basal salts, $0.1 \%(\mathrm{wt} / \mathrm{vol})$ glucose, and $0.1 \%$ (wt/vol) yeast extract; the $\mathrm{pH}$ was adjusted to 3.0 at $70^{\circ} \mathrm{C}$ with $10 \% \mathrm{H}_{2} \mathrm{SO}_{4}$ for most experiments and with $\mathrm{HCl}$ for the nutritional experiments. Microbial growth was monitored by measuring $A_{520}$, and cell numbers were determined by using a Thoma bacterial counting chamber. To examine chemolithoautotrophic growth, the new isolate and the type strains were cultivated in modified Allen's medium without glucose and yeast extract in the presence of $0.1 \%$ (wt/vol) elemental sulfur, potassium tetrathionate, or $\mathrm{FeS}$ as an energy source. When $\mathrm{H}_{2} \mathrm{~S}$ was used as an energy source, air containing $0.1 \%$ (vol $/ \mathrm{vol}) \mathrm{H}_{2} \mathrm{~S}$ was bubbled into modified Allen's medium without glucose and yeast extract at a constant flow rate $\left(30 \mathrm{ml}\right.$ of $\mathrm{H}_{2} \mathrm{~S}$ per min per $10 \mathrm{ml}$ of culture). To examine anaerobic and chemolithoautotrophic growth, the new isolate and the type strains were cultivated in modified Allen's medium without glucose and yeast extract in the presence of $0.1 \%(\mathrm{wt} / \mathrm{vol})$ elemental sulfur, $0.001 \%(\mathrm{wt} / \mathrm{vol})$ resazurin, and $0.1 \%$ (wt/vol) sodium sulfate under an $\mathrm{H}_{2}-\mathrm{CO}_{2}(4: 1, \mathrm{vol} / \mathrm{vol})$ gas phase. To examine the potential of the new isolate and the type strains to utilize sugars and amino acids as carbon sources, the organisms were cultivated in modified Allen's medium without glucose and yeast extract in the presence of each sugar or amino acid at a concentration of 0.1 or $1.0 \%$ (wt/vol). To determine whether $0.1 \%$ yeast extract was required, modified Allen's medium without glucose and yeast extract was used as the basal medium.

Isolation of microbial strains. $\mathrm{H}_{2} \mathrm{~S}$-containing water was obtained from a hot spring in a geothermal field at Owaku-dani in Hakone National Park (Hakone, Kanagawa, Japan). A 1-ml water sample was inoculated into $10 \mathrm{ml}$ of modified Allen's medium ( $\mathrm{pH} 2.5$ ) and incubated at $70^{\circ} \mathrm{C}$. After the culture became turbid (after about 1 week), a portion of the culture $(1.0 \mathrm{ml})$ was transferred into $9.0 \mathrm{ml}$ of fresh medium, and cultivation was continued. When the growth became exponential, portions of the culture were streaked onto $1.0 \%$ Gelrite (Difco Laboratories, Detroit, Mich.) plates containing modified Allen's medium, and the plates were incubated at $70^{\circ} \mathrm{C}$. An isolated colony was transferred into broth, the culture was incubated, and portions were streaked onto plates as described above. This procedure was repeated once more. The isolate obtained was maintained by transferring it to fresh medium each week.

Electron microscopy. Cells were fixed with $4.0 \%$ glutaraldehyde for $8 \mathrm{~h}$ and postfixed with $1.0 \%$ osmic acid for $4 \mathrm{~h}$. After dehydration in an ethanol series and substitution of ethanol with propylene oxide, the cells were embedded in Epon 812 resin (TAAB, Berkshire, England), and the resin was polymerized at $60^{\circ} \mathrm{C}$ for $12 \mathrm{~h}$, as described by Kellenberger et al. (13). Thin sections prepared with a ultramicrotome were stained with $10 \%$ uranyl acetate and $0.02 \%$ lead citrate and observed with a model JEM 100B electron microscope (JEOL, Tokyo, Japan) operated at $80 \mathrm{kV}$, as described by Kellenberger et al. (13). To observe the cell surface by negative staining, cells were washed one to three times with $20 \mathrm{mM}$ 
Tris- $\mathrm{HCl}(\mathrm{pH} 7.5$ ) and centrifuged at $10,000 \times g$ for 1 min and then spread onto a water surface, as described previously (28). Intact or broken cells, cell membrane fragments, and cell ghosts floating on the surface were picked up with carbon-coated grids and stained with $1.0 \%$ uranyl acetate; they were then observed by electron microscopy directly or after rotary shadowing with Pt-Pd (4:1) at an angle of $\tan ^{1}(1 / 10)$, as described by Marmur (19).

Determination of the $\mathbf{G}+\mathbf{C}$ content. Genomic DNA was isolated from microorganisms as described previously (19). The guanine-plus-cytosine $(\mathrm{G}+\mathrm{C})$ content of the DNA was determined by $\mathrm{CsCl}$ isopycnic centrifugation by using a type 70PRS rotor (Hitachi Koki Co., Ltd., Hitachi, Japan) at 40,000 rpm for $72 \mathrm{~h}$, as described by De Ley (3). The distribution of DNA in the fraction was determined by the method of Kissane and Robins (15). E. coli IAM 1264 DNA (G+C content, $51.6 \mathrm{~mol} \%$ ) was used as the standard in the buoyant density analysis.

Lipid analysis. Total lipids were extracted from wet cells (packed volume, 1 $\mathrm{ml}$ ) with $4.0 \mathrm{ml}$ of chloroform-methanol-water $(1: 2: 0.5, \mathrm{vol} / \mathrm{vol} / \mathrm{vol})$ with sonication. The extraction procedure was repeated three times. After degradation of the total lipids with acid methanolysis as described by Furuya et al. (8), the lipid cores were separated by thin-layer chromatography (TLC) on silica gel plates (type HPTLC; catalog no. 5641; Merck, Rahway, N.J.). The spots on the TLC plates were visualized by spraying the plates with $50 \% \mathrm{H}_{2} \mathrm{SO}_{4}$ and then heating them at $140^{\circ} \mathrm{C}$ for $10 \mathrm{~min}$. A quantitative analysis of the spots on the TLC plates was performed by a TLC-densitometry procedure by using a chromatoscanner (model CS-930; Shimadzu, Kyoto, Japan).

DNA-DNA hybridization. DNA was isolated from microorganisms as described by Marmur (19). The DNA was labeled with $\left.{ }^{3} \mathrm{H}\right] \mathrm{dTMP}$ by nick translation by using a nick translation kit (Takara Shuzo Co., Ltd., Kyoto, Japan), and $0.1 \mu \mathrm{g}$ of the resulting labeled, sonicated DNA was the probe used for hybridization. After denaturation of the DNA, $10 \mu \mathrm{g}$ of unlabeled DNA was immobilized on a nitrocellulose membrane (type HAWP; pore size, $0.45 \mu \mathrm{m}$; Millipore, Bedford, Mass.), and DNA-DNA hybridization experiments were performed by the membrane filter method, as described by Suzuki et al. (27).

16S rRNA sequencing. RNA was extracted from microorganisms, and complete sequences of the 16S rRNA were determined by the reverse transcriptase method (17). The following nucleotide primers that were complementary to universally conserved regions were used: TCCGGTTGATCCTGCCGGA (position 10, forward direction), GCGGACGGCTGAGTAACA (position 120, forward direction), CCTATAACGGGTAGGGGCCG (position 290, forward direction), CTACGGGGCGCACCAG (position 350, forward direction) CAGCCGCCGCGGTAATAC (position 520, forward direction), GGTACTCC CGGAGTAGGGGC (position 700, forward direction), GATTAGATACCCTG GTAG (position 800, forward direction), AAACTTAAAGGAATTGGC (position 920, forward direction), GTTAAGTCAGGCAACGAGCG (position 1110 forward direction), CACGCGGGTTACAATGGC (position 1240, forward direction), CCTTGCACACACCGCCCGTC (position 1240, forward direction), TGTTACTCAGCCGTCCGC (position 120 , reverse direction), CGGCCCCT ACCCGTTATAGG (position 290, reverse direction), CTGGTGCGGCCC CGTAG (position 350, reverse direction), GTATTACCGCGGCGGCTG(position 520, reverse direction), GCCCCTACTCCGGGAGTACC (position 700 reverse direction), CTACCAGGGTATCTAATC (position 800, reverse direction), GCCAATTCCTTTAAGTTT (position 920, reverse direction), CGCTCGTTGCCTGACTTAAC (position 1110, reverse direction), GCCATTG TAACCCGCGTG (position 1240, reverse direction), GACGGGCGGTGTGTG CAAGG (position 1400, reverse direction), and GAGGTGATCCAGCCGC AGG (position 1540, reverse direction) (E. coli 16S rRNA numbering). These primers were made with DNA synthesizer (model 380B; Applied Biosystems, Foster City, Calif.). Levels of homology and phylogenetic distances were determined by the method of Kimura (14). A phylogenetic tree was reconstructed by using the algorithm of the neighbor-joining method (22) and the phylogenetic distance values. The statistical significance of the positions of some groups on the tree was reexamined by using the bootstrap method of Felsenstein (7) and 1,000 replicates.

Nucleotide sequence accession numbers. The $16 \mathrm{~S}$ rRNA nucleotide sequence of strain HO1-1 and S. acidocaldarius DSM $639^{\mathrm{T}}$ have been deposited in the DDBJ, EMBL, and GenBank databases under accession numbers D14052 and D14053, respectively.

\section{RESULTS AND DISCUSSION}

Three isolates were obtained from hot spring water containing mud $\left(\mathrm{pH} 1.5\right.$; temperature, $\left.91.5^{\circ} \mathrm{C}\right)$ which was obtained near a point from which $\mathrm{H}_{2} \mathrm{~S}$-containing gas was actively gushing out in a lava field at Owaku-dani, Hakone, Japan. Strain HO1-1 was characterized in detail.

Strain HO1-1 did not grow in modified Allen's medium in the absence of glucose and yeast extract, but it did grow when the medium was supplemented with yeast extract under aerobic conditions at a low $\mathrm{pH}$ value and high temperature (Fig. 1 and Tables 1 and 2). This strain did not grow under anaerobic conditions with an $\mathrm{H}_{2}-\mathrm{CO}_{2}$ gas phase in medium supplemented
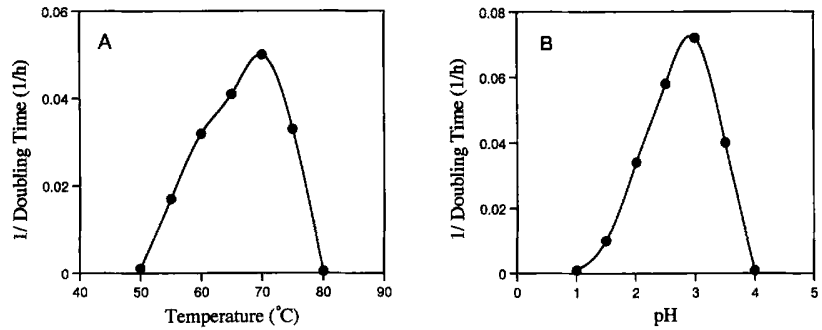

FIG. 1. Temperature (A) and $\mathrm{pH}$ (B) requirements for growth of strain HO1-1. Strain HO1-1 was cultivated under the aerobic conditions described in the text.

with glucose and yeast extract, regardless of the presence of elemental sulfur (data not shown). It also grew when the elemental sulfur was replaced with other inorganic forms of sulfur (Table 2). Thus, strain HO1-1 is able to obtain energy by oxidizing sulfur.

Strain HO1-1 grew at $\mathrm{pH} 1.0$ to 4.0 and at 50 to $80^{\circ} \mathrm{C}$ (Fig. 1). The optimal $\mathrm{pH}$ and optimal temperature for growth were 3.0 and $70^{\circ} \mathrm{C}$, respectively (Fig. 1). Thus, this strain is apparently an extreme thermophiles which is acidophilic.

Strain HO1-1 were spherical or irregular polyhedrons (lobed) with diameters of 0.9 to $1.1 \mu \mathrm{m}$ and had no flagella; motility was not observed at any phase of growth (Fig. $2 \mathrm{~A}$ and Table 1). The cells had a plasma membrane that was about 4 $\mathrm{nm}$ thick and was surrounded by a layer (cell wall) that was about $21 \mathrm{~nm}$ thick (Fig. 2A). The surface of the layer was composed of regularly arranged structures that had a wavy appearance (Fig. 2B). The layer was associated with a networklike structure throughout the surface, and the meshes of the network were equal in size and were located at an angle of $60^{\circ}$ with respect to each other at constant intervals, as shown by the negatively stained preparations (Fig. 2C and D).

The characteristics of strain HO1-1, including its lobed-cells, its acidothermophilic mode of life, its aerobic metabolism, and its lithotrophic dependence on sulfur for growth, are consistent with the characteristics of the family Sulfolobaceae (25).

An analysis of the structure of the lipid core of strain HO1-1 by TLC revealed that this strain produced two major spots, which corresponded to caldarchaeol (26) and calditoglycerocaldiarchaeol (CGTE) (20) (Fig. 3). We estimated that CGTE accounted for about $80 \%$ of the core lipid content by densitometry of the TLC spots. Essentially the same results were obtained for $S$. acidocaldarius and $S$. solfataricus (Fig. 3). The spot corresponding to strain HO1-1 CGTE on the TLC in Fig. 3 was also analyzed by fast atom bombardment-mass spectrometry and positive-ion fast atom bombardment spectroscopy, and the presence of CGTE molecules with various degrees of cyclization was confirmed (detailed chemical structures will be reported elsewhere). CGTE has been found only in members of the Sulfolobaceae $(4,6,18)$.

The family Sulfolobaceae comprises the genera Sulfolobus, Acidianus, and Metallosphaera $(4,10,23)$. Recently, it has been suggested that members of the genus Desulfurolobus which previously was considered a genus that belongs to the family Sulfolobaceae, should be placed in the genus Acidianus (24, 32). Strain HO1-1 can be distinguished from the genus Acidianus because strain HO1-1 does not grow under anaerobic conditions, while Acidianus strains grow under both aerobic and anaerobic conditions $(2,9,11,23,31,32)$.

The $\mathrm{G}+\mathrm{C}$ content of genomic DNA is a useful way to distinguish the genera Sulfolobus, Acidianus, and Metallosphaera, whose $\mathrm{G}+\mathrm{C}$ contents have been reported to be 34 to 39,30 to 
TABLE 1. Morphological, physiological, and biophysical properties of strain HO1-1 and other Sulfolobus strains

\begin{tabular}{|c|c|c|c|c|c|}
\hline Characteristic & Strain HO1-1 & S. acidocaldarius DSM $639^{\mathrm{T}}$ & S. solfataricus DSM $1616^{\mathrm{T}}$ & S. shibatae DSM $5389^{\mathrm{T} a}$ & S. metallicus DSM $6482^{T h}$ \\
\hline \multicolumn{6}{|l|}{ Colony morphology } \\
\hline Color & Dark yellow & Dark yellow & Grayish & Pale $\tan$ & \\
\hline Shape & Smooth, flat & Smooth, flat & Smooth, flat & & \\
\hline $\operatorname{Diam}(\mu \mathrm{m})$ & $0.5-1.0$ & $0.5-1.0$ & 2.0 & & \\
\hline Cell shape & Lobed & Lobed & Lobed & & Irregular, coccoid \\
\hline Cell diam $(\mu \mathrm{m})$ & $0.9-1.1$ & $0.8-1.0$ & $0.8-2.0$ & $0.7-1.5$ & 1.5 \\
\hline Flagella & - & - & - & & \\
\hline Motility & - & - & - & Weak & \\
\hline Cell wall & + & + & + & + & + \\
\hline Temp range for growth $\left({ }^{\circ} \mathrm{C}\right)$ & $50-80$ & $55-85$ & $55-85$ & & $50-75$ \\
\hline Optimum temp $\left({ }^{\circ} \mathrm{C}\right)$ & 70 & 70 & 70 & 81 & 65 \\
\hline $\mathrm{pH}$ range for growth & $1.0-4.0$ & $2.0-4.0$ & $2.0-4.0$ & & $1.0-3.5$ \\
\hline Optimum $\mathrm{pH}$ & 3.0 & 2.5 & 4.5 & 3.0 & \\
\hline $\mathrm{G}+\mathrm{C}$ content $(\mathrm{mol} \%)$ & $38.4 \pm 1.5^{c}$ & $38.2 \pm 1.5^{c}$ & $36^{d}$ & 34.6 & 37 \\
\hline
\end{tabular}

${ }^{a}$ Data from reference 9.

${ }^{b}$ Data from reference 11 .

Mean \pm standard deviation from three experiments.

${ }^{d}$ Data from reference 31 .

33 , and 45 to $47 \mathrm{~mol} \%$, respectively $(9,10,11,23,32)$. The $\mathrm{G}+\mathrm{C}$ content of strain HO1-1 was determined by the buoyant density method. As Sulfolobus DNA preparations apparently contain materials which affect the DNA $\mathrm{G}+\mathrm{C}$ content determinations (13; unpublished data), we determined DNA G+C contents directly with centrifuged fractions by using the fluorometric method. The $\mathrm{G}+\mathrm{C}$ content of strain HO1-1 was esti- mated to be $38.4 \mathrm{~mol} \%$, a value that was very similar to the value obtained for S. acidocaldarius DSM $639^{\mathrm{T}}(38.2 \mathrm{~mol} \%)$ (Table 1). Thus, strain HO1-1 seems to belong to the genus Sulfolobus and not to the genus Acidianus or the genus Metallosphaera.

Four Sulfolobus species, S. acidocaldarius, S. solfataricus, Sulfolobus shibatae, and Sulfolobus metallicus, have been de-

TABLE 2. Utilization of sulfur compounds, sugars, amino acids, and yeast extract for growth ${ }^{a}$

\begin{tabular}{|c|c|c|c|c|c|}
\hline Characteristic & Strain HO1-1 & S. acidocaldarius DSM $639^{\mathrm{T}}$ & S. solfataricus DSM $1616^{\mathrm{T}}$ & S. shibatae DSM $5389^{\mathrm{Th}}$ & S. metallicus DSM $6482^{\mathrm{Tc}}$ \\
\hline \multicolumn{6}{|l|}{ Utilization of sulfur sources } \\
\hline Elemental S & + & + & + & + & + \\
\hline $\mathrm{FeS}$ & ++ & ++ & + & & - \\
\hline Tetrathionate & + & + & + & & \\
\hline $\mathrm{H}_{2} \mathrm{~S}$ & + & + & + & & \\
\hline \multicolumn{6}{|l|}{ Utilization of sugars $^{d}$} \\
\hline D-Arabinose & - & \pm & \pm & + & - \\
\hline D-Ribose & - & - & \pm & & - \\
\hline D-Xylose & - & - & \pm & & - \\
\hline D-Fructose & - & \pm & \pm & & - \\
\hline D-Galactose & - & - & ++ & + & - \\
\hline D-Glucose & - & + & ++ & + & - \\
\hline D-Mannose & - & ++ & ++ & + & - \\
\hline L-Rhamnose & - & - & - & & \\
\hline Lactose & - & - & ++ & + & - \\
\hline Maltose & $( \pm)$ & + & $+t$ & + & \\
\hline Sucrose & - & ++ & + & + & - \\
\hline Raffinose & - & ++ & + & + & - \\
\hline \multicolumn{6}{|l|}{ Utilization of amino acidse } \\
\hline L-Aspartic acid & - & \pm & \pm & & \\
\hline L-Glutamic acid & $( \pm)$ & + & \pm & & - \\
\hline L-Tryptophan & $( \pm)$ & + & - & & \\
\hline Utilization of yeast extract & ++ & ++ & ++ & ++ & - \\
\hline
\end{tabular}

\footnotetext{
a The microbial strains were incubated at $70^{\circ} \mathrm{C}$ for 1 week in the presence of various substances under the conditions described in the text. We tested each sugar and amino acid at concentrations of 0.1 and $1.0 \%$; the same results were obtained with both concentrations, except as indicated below. The amount of growth was expressed as the ratio ( $\mathrm{R}$ ) of $A_{520}$ after 1 week of incubation to $A_{520}$ before incubation (which was 0.05 ), as follows:,$- \mathrm{R}=1 ; \pm, 1<\mathrm{R} \leq 2$ ( $\mathrm{R} \geq 2$ after 2 weeks of incubation); ,$+ 2<\mathrm{R} \leq 10 ;++, \mathrm{R}>10 ;( \pm), \mathrm{R}=1$ and $1<\mathrm{R} \leq 2$ in the presence of 0.1 and $1.0 \%$ test substrate, respectively.

${ }^{b}$ Data from reference 9.

${ }^{c}$ Data from reference 11 .

${ }^{d}$ The sugars that were not utilized were inositol, D-mannitol, and D-sorbitol.

${ }^{\prime}$ The amino acids that were not utilized were L-alanine, L-arginine, L-asparagine, L-cysteine, L-glutamine, L-glycine, L-histidine, L-isoleucine, L-leucine, L-lysine, L-methionine, L-ornithine, L-phenylalanine, L-proline, L-serine, L-threonine, and L-tyrosine.
} 

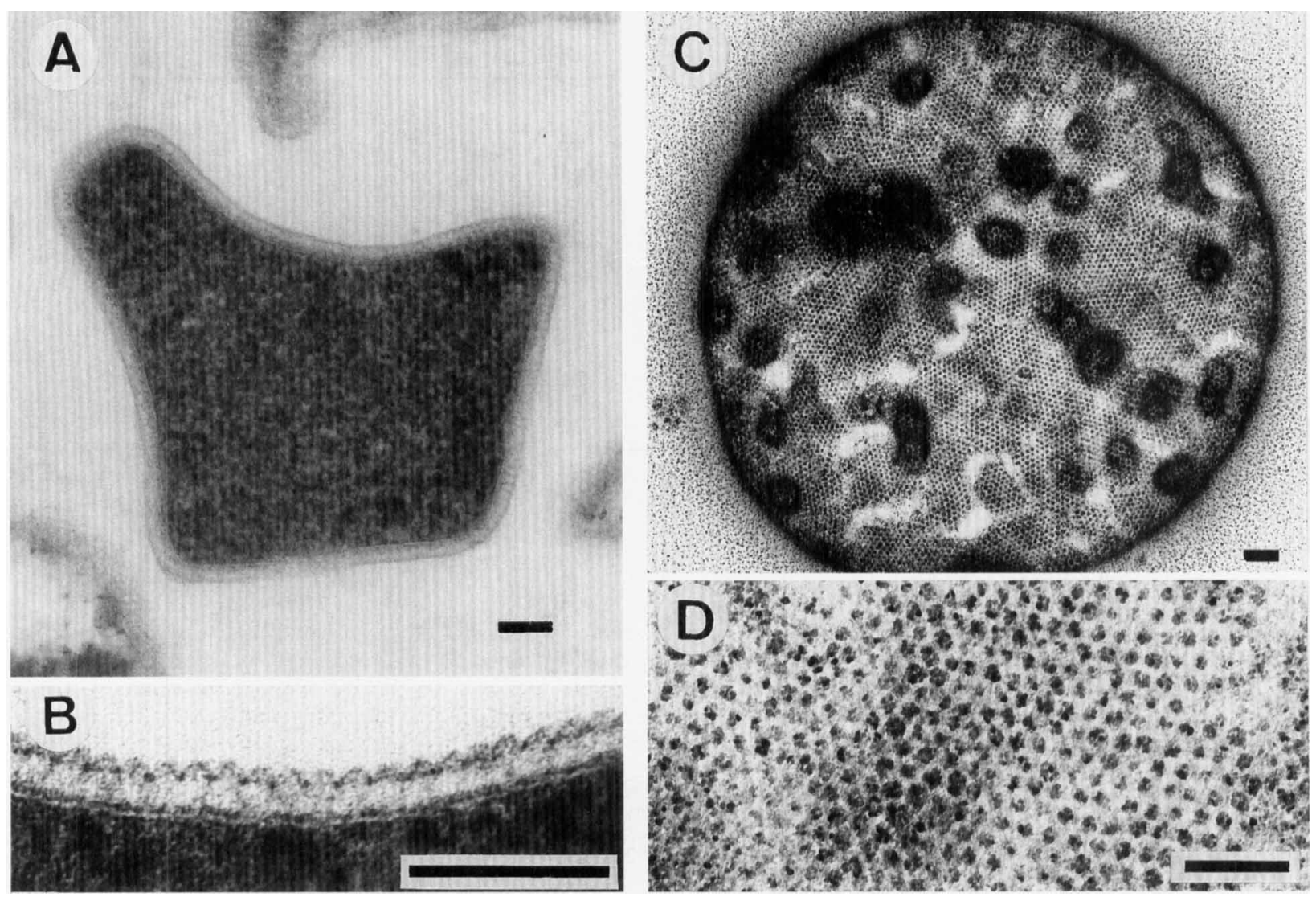

FIG. 2. Electron micrographs of microbial cells. (A and B) Thin sections of a strain HO1-1 cell. Panel B shows the peripheral region of the cell. (C and D) Negatively stained cell envelope. A ghost of a strain HO1-1 cell was stained negatively, shadowed, and observed by electron microscopy, as described in the text. Panel D is a higher magnification of the cell shown in panel C. Bars $=0.1 \mu \mathrm{m}$.

scribed previously $(2,9,11,31,32)$. Although these four species are similar morphologically, are all acidothermophiles, and have similar genomic DNA G + C contents (Table 1) $(2,9$, $11,31,32$ ), they can be distinguished from each other by their nutritional requirements. Three of these species, $S$. acidocaldarius, S. solfataricus, and S. shibatae, are facultative chemo-

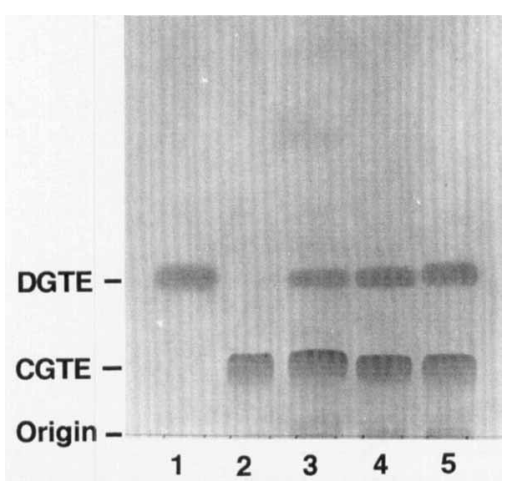

FIG. 3. Analysis of the lipids of strain HO1-1 and related organisms. The core lipids of the microorganisms were analyzed by TLC as described in the text. The plate was first developed with chloroform-methanol $(4: 1$, vol/vol $)$ up to $3 \mathrm{~cm}$ and then dried and redeveloped in the same direction with hexane-ether-acetic acid (30:20:1, vol/vol/vol) up to the top. Lanes 1 and 2 contained authentic caldarchaeol (DGTE) and CGTE, respectively, as controls. Lanes 3, 4 and 5 contained the core lipids of strain HO1-1, S. acidocaldarius, and S. solfataricus, respectively. lithoautotrophs, whereas $S$. metallicus is an obligate autotroph $(2,9,11,31,32)$. Strain HO1-1, S. acidocaldarius, $S$. solfataricus, and $S$. shibatae utilize organic nutrients in yeast extract and some sugars and amino acids, but $S$. metallicus cannot utilize these compounds (Table 2); this characteristic distinguishes strain HO1-1 from $S$. metallicus. We compared the abilities of strain HO1-1 and the three facultative chemolithoautotrophs to utilize carbon compounds (Table 2). A total of 15 sugars were tested, and strain HO1-1 grew slightly in the presence of $1.0 \%$ maltose, while $S$. acidocaldarius and $S$. solfataricus grew in the presence of 0.1 and $1.0 \%$ maltose and several other sugars (Table 2). S. acidocaldarius could be distinguished from $S$. solfataricus by its ability to utilize galactose and lactose (Table 2). We found that $S$. shibatae has a sugar utilization profile that is similar to that of $S$. solfataricus and quite different from that of strain HO1-1 (Table 2). When amino acids were tested, strain HO1-1 grew weakly in the presence of $1.0 \%$ glutamic acid and $1.0 \%$ tryptophan, while $S$. acidocaldarius grew weakly in the presence of $1.0 \%$ glutamic acid and $1.0 \%$ tryptophan, while $S$. acidocaldarius grew weakly in the presence of $0.1 \%$ glutamic acid and $0.1 \%$ tryptophan and $S$. solfataricus grew weakly in the presence of 0.1 and $1.0 \%$ aspartic acid and 0.1 and $1.0 \%$ glutamic acid (Table 2). Thus, strain HO1-1 could be distinguished from $S$. acidocaldarius, $S$. solfataricus, and $S$. shibatae on the basis of utilization of carbon compounds, just as $S$. acidocaldarius can be distinguished from $S$. solfataricus and $S$. shibatae on the basis of this characteristic. 
TABLE 3. Levels of DNA-DNA hybridization between the Sulfolobus strains

\begin{tabular}{lccc}
\hline \multirow{2}{*}{$\begin{array}{c}\text { Source of } \\
\text { filter-bound DNA }\end{array}$} & \multicolumn{3}{c}{$\begin{array}{c}\% \text { of }\left[{ }^{3} \mathrm{H}\right] \text {-labeled probe DNA associated with } \\
\text { filter-bound DNA }\end{array}$} \\
\cline { 2 - 4 } & $\begin{array}{c}\text { Strain } \\
\text { HO1-1 }\end{array}$ & $\begin{array}{c}\text { S. acidocaldarius } \\
\text { DSM } 639^{\mathrm{T}}\end{array}$ & $\begin{array}{c}\text { S. solfataricus } \\
\text { DSM } 1616^{\mathrm{T}}\end{array}$ \\
\hline $\begin{array}{l}\text { Strain HO1-1 } \\
\text { S. acidocaldarius }\end{array}$ & 100 & $2.8 \pm 0.5$ & $6.1 \pm 2.8$ \\
S. solfataricus & $3.6 \pm 3.4$ & 100 & $2.8 \pm 1.8$ \\
E. coli IAM & $<1.1 \pm 2.6$ & $6.3 \pm 2.6$ & 100 \\
$\quad \begin{array}{l}1264 \\
\text { Calf thymus }\end{array}$ & $<1$ & $<1$ & $<1$ \\
\hline
\end{tabular}

${ }^{a}$ Mean \pm standard deviation from three experiments.

Similarity of genomic DNAs as determined by DNA-DNA hybridization has been used to distinguish species (12). The lack of genetic relatedness of strain HO1-1 to previously described species was revealed by the levels of hybridization of genomic DNAs (Table 3). The levels of hybridization between strain HO1-1 and $S$. acidocaldarius DNAs and between strain HO1-1 and $S$. solfataricus DNAs were estimated to be 3.6 and $3.1 \%$, respectively, and the level of hybridization between $S$. acidocaldarius and $S$. solfataricus DNAs was $6.1 \%$ (Table 3). These results indicate that strain HO1-1 is not a member of $S$. acidocaldarius or $S$. solfataricus.

To examine the taxonomic position of strain HO1-1 at the generic level, we determined the base sequences of the $16 \mathrm{~S}$ rRNAs of strain HO1-1 (1,451 nucleotides) and S. acidocaldarius DSM $639^{\mathrm{T}}$, the type strain of the type species of the genus Sulfolobus. Sequence data for S. solfataricus IFO $15331^{\mathbf{T}}$ (derived from DSM $1616^{\mathrm{T}}$ ) were provided by Y. H. Itoh (11a). Sequence data for $S$. solfataricus "P1" (not strain $\mathrm{P} 1^{\mathrm{T}}$ deposited in the Deutsche Sammlung von Mikroorganismen und Zellkulturen as strain DSM $1616^{\mathrm{T}}$ were reported by Olsen et al. (21), and the level of sequence similarity between this strain and $S$. acidocaldarius DSM $639^{\mathrm{T}}$ was $99.9 \%$ (unpublished data). Recently, strain "P1" proved to be erroneously labeled and was assigned to $S$. acidocaldarius (30). The levels of similarity between strain HO1-1 16S rRNA and $S$. acidocaldarius, $S$. solfataricus, and $S$. shibatae 16 S rRNAs were $89.8,89.3$, and $89.4 \%$, respectively, when 1,346 nucleotides were compared. The levels of similarity between strain HO1-1 and members of other genera were less than $87.5 \%$. The levels of similarity for the three Sulfolobus species and strain HO1-1 were 89.3 to $92.1 \%$, except when $S$. solfataricus and $S$. shibatae were compared (level of similarity, 99.6\%) (Table 4). Figure 4 shows a reconstructed phylogenetic tree. As Table 4 and Fig. 4 show, strain HO1-1 seems to be closely related to the genus Sulfolobus, but different from previously described Sulfolobus species.

On the basis of phenotypic characteristics and genetic distinctness, we concluded that strain HO1-1 represents a new Sulfolobus species, and we propose the name Sulfolobus hakonensis for this species.

Description of Sulfolobus hakonensis sp. nov. Sulfolobus hakonensis (ha. ko. nen'sis. M.L. masc. adj. hakonensis, pertaining to Hakone National Park, Japan, the location of the hot spring from which the organism was isolated). The cells are lobed, gram-negative cocci (diameter, 0.9 to $1.1 \mu \mathrm{m}$ ) and are surrounded by cell wall which consists of regularly arranged structures. Growth occurs at temperatures between 50 and $80^{\circ} \mathrm{C}$ (optimum temperature, $70^{\circ} \mathrm{C}$ ) and at $\mathrm{pH} 1.0$ to 4.0 (optimum $\mathrm{pH}, 3.0$ ). Aerobic and facultatively chemolithoautotrophic. Lithotrophic growth occurs on elemental sulfur, ferrous sulfide, sodium tetrathionate, and hydrogen sulfide. Weak growth occurs in the presence of $1.0 \%$ maltose, glutamic acid, or tryptophan as a sole carbon and energy source. The $\mathrm{G}+\mathrm{C}$ content of the genomic DNA is $38.4 \mathrm{~mol} \%$. The main cellular lipids are CGTE and caldarchaeol. The levels of similarity between the 16S rRNA of $S$. hakonensis and the $16 \mathrm{~S}$ rRNAs of $S$. acidocaldarius DSM $639^{\mathrm{T}}, S$. solfataricus IFO $15331^{\mathrm{T}}$, and $S$. shibatae DSM $5389^{\mathrm{T}}$ are $89.8,89.3$, and $89.4 \%$, respectively. The type strain is strain HO1-1 (= IAM $14250=$ JCM $8857=$ DSM $7519=$ ATCC 51241).

TABLE 4. Levels of similarity and phylogenetic distances ( $K_{\text {nuc }}$ values) for 1,346-nucleotide regions of the 16S rRNA genes of strain HO1-1 and thermophilic microorganisms

\begin{tabular}{|c|c|c|c|c|c|c|c|c|c|c|c|}
\hline \multirow[b]{2}{*}{ Organism } & \multirow[b]{2}{*}{$\begin{array}{l}\text { Nucleotide sequence } \\
\text { accession no. }\end{array}$} & \multicolumn{10}{|c|}{$\%$ Similarity or $K_{\text {nuc }}$ value ${ }^{a}$} \\
\hline & & 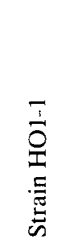 & 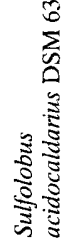 & 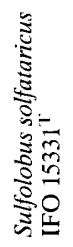 & 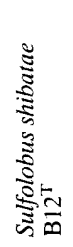 & 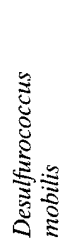 & 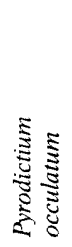 & 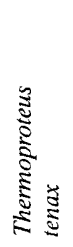 & 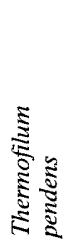 & 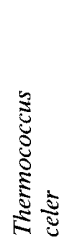 & 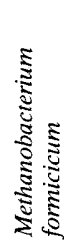 \\
\hline Strain HO1-1 & & & 89.8 & 89.3 & 89.4 & 87.4 & 87.5 & 83.3 & 83.7 & 79.0 & 75.5 \\
\hline $\begin{array}{l}\text { Sulfolobus acidocaldarius } \\
\text { DSM } 639^{\mathrm{T}}\end{array}$ & & 9.6 & & 92.1 & 92.1 & 89.3 & 89.8 & 85.5 & 86.0 & 79.9 & 76.5 \\
\hline $\begin{array}{l}\text { Sulfolobus solfataricus } \\
\text { IFO } 15331^{\mathrm{T}}\end{array}$ & D26490 & 10.1 & 7.4 & & 99.6 & 88.6 & 89.1 & 85.1 & 86.8 & 79.6 & 76.8 \\
\hline Sulfolobus shibatae $\mathrm{B} 12^{\mathrm{T}}$ & M32504 & 10.1 & 7.3 & 0.3 & & 88.6 & 89.2 & 85.2 & 86.9 & 79.6 & 77.0 \\
\hline Desulfurococcus mobilis & M36474 & 12.1 & 10.1 & 10.8 & 10.8 & & 94.1 & 88.0 & 88.6 & 84.1 & 78.7 \\
\hline Pyrodictium occulatum & M21087 & 12.0 & 9.5 & 10.3 & 10.2 & 5.3 & & 89.4 & 90.5 & 85.1 & 79.3 \\
\hline Thermoproteus tenax & M35966 & 16.5 & 14.0 & 14.4 & 14.3 & 11.4 & 10.0 & & 89.2 & 82.7 & 76.5 \\
\hline Thermofilum pendens & $\mathrm{X} 14835$ & 16.1 & 13.5 & 12.7 & 12.5 & 10.8 & 8.9 & 10.2 & & 84.1 & 78.9 \\
\hline Thermococcus celer & M21529 & 21.5 & 20.3 & 20.8 & 20.8 & 15.6 & 14.5 & 17.1 & 15.6 & & 82.0 \\
\hline Methanobacterium formicicum & M36508 & 26.1 & 24.7 & 24.3 & 24.1 & 22.0 & 21.3 & 24.9 & 21.8 & 8.2 & \\
\hline
\end{tabular}

${ }^{a}$ The values on the upper right are levels of similarity (expressed as percentages), and the values on the lower left are $K_{\text {nuc }}$ values. 


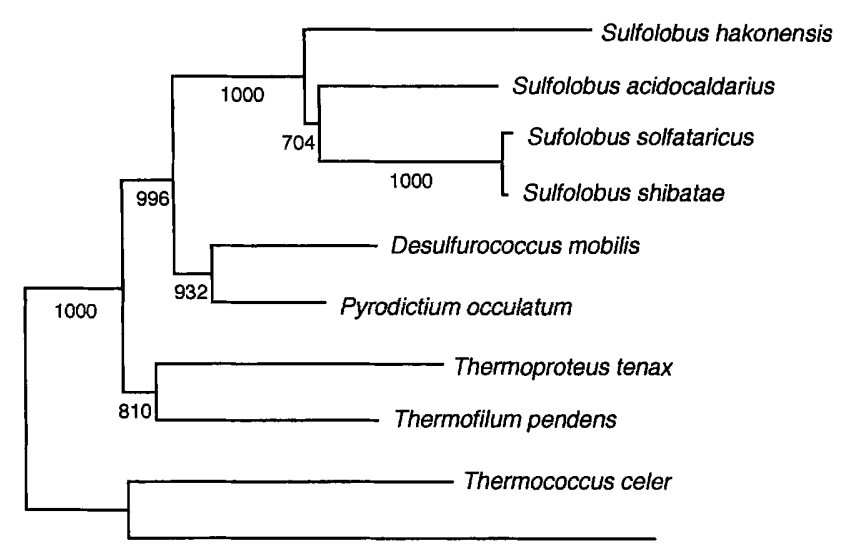

Methanobacterium formicicum

0.02 Knuc

FIG. 4. Phylogenetic relationships among strain HO1-1 (S. hakonensis) and related microorganisms. The phylogenetic tree was reconstructed by the neighbor-joining method on the basis of 16S rRNA sequences data. The numbers are the bootstrap values obtained with 1,000 replicates. See Table 4 for the strains used in this analysis.

\section{ACKNOWLEDGMENTS}

We thank Yuko H. Itoh, Soka University, for providing the $16 \mathrm{~S}$ rRNA sequence of $S$. solfataricus IFO $15331^{\mathrm{T}}$.

This work was supported in part by grants-in-aid for scientific research from the Ministry of Education, Science and Culture of Japan.

\section{REFERENCES}

1. Brierley, C. L., and J. A. Brierley. 1973. A chemoautotrophic and thermophilic microorganism isolated from an acid hot spring. Can. J. Microbiol. 19:183-188.

2. Brock, T. D., K. M. Brock, R. T. Belly, and R. L. Weiss. 1972. Sulfolobus: a new genus of sulfur-oxidizing bacteria living at low $\mathrm{pH}$ and high temperature. Arch. Mikrobiol. 84:54-68.

3. De Ley, J. 1970. Reexamination of the association between melting point, buoyant density, and chemical base composition of deoxyribonucleic acid. J. Bacteriol. 101:738-754.

4. De Rosa, M., and A. Gambacorta. 1988. The lipids of archaebacteria. Prog. Lipid Res. 27:153-157.

5. De Rosa, M., A. Gambacorta, and J. D. Bu'Lock. 1975. Extremely thermophilic acidophilic bacteria convergent with Sulfolobus acidocaldarius. J. Gen. Microbiol. 86:156-164.

6. De Rosa, M., A. Gambacorta, B. Nicolaus, B. Chappe, and P. Albrecht. 1983. Isoprenoid ethers; backbone of complex lipids of the archaebacterium Sulfolobus solfataricus. Biochim. Biophys. Acta 753:249-256.

7. Felsenstein, J. 1985. Confidence limits on phylogenies: an approach using the bootstrap. Evolution 39:783-791.

8. Furuya, T., T. Nagano, T. Itoh, and H. Kaneko. 1980. A thermophilic acidophilic bacterium from hot spring. Agric. Biol. Chem. 44:517-521.

9. Grogan, D., P. Palm, and W. Zillig. 1990. Isolate B12, which harbours a virus-like element, represents a new species of the archaebacterial genus Sulfolobus, Sulfolobus shibatae, sp. nov. Arch. Microbiol. 154:594-599.

10. Huber, G., C. Spinnler, A. Gambacorta, and K. O. Stetter. 1989. Metallosphaera sedula gen. and sp. nov. represents a new genus of aerobic, metalmobilizing, thermoacidophilic archaebacteria. Syst. Appl. Microbiol. 12:3847.
11. Huber, G., and K. O. Stetter. 1991. Sulfolobus metallicus, sp. nov., a novel strictly chemolithoautotrophic thermophilic archaeal species of metal-mobilizers. Syst. Appl. Microbiol. 14:372-378.

11a.Itoh, Y. H. Personal communication.

12. Johnson, J. L. 1984. Contribution of nucleic acid studies to bacterial taxonomy, p. 11. In N. R. Krieg and J. G. Holt (ed.), Bergey's manual of systematic microbiology, vol. 1. The Williams \& Wilkins Co., Baltimore.

13. Kellenberger, E., A. Ryter, and J. Séchand. 1958. Electron microscope study of DNA-containing plasma. II. Vegetative and mature phage DNA as compared with normal bacterial nucleoids in different physiological states. J. Biophys. Biochem. Cytol. 4:671-676.

14. Kimura, M. 1983. The natural theory of molecular evolution, p. 55-97. Cambridge University Press, Cambridge.

15. Kissane, J. M., and E. Robins. 1958. The fluorometric measurement of deoxyribonucleic acid in animal tissues with special reference to the central nervous system. J. Biol. Chem. 233:184-188.

16. Kurosawa, N., and Y. H. Itoh. 1993. Nucleotide sequence of the 16S rRNA gene from thermoacidophilic archaea Sulfolobus acidocaldarius ATCC 33909. Nucleic Acids Res. 21:357.

17. Lane, D. J., B. Pace, G. J. Olsen, D. A. Stahl, M. L. Sogin, and N. R. Pace. 1985. Rapid determination of $16 \mathrm{~S}$ ribossomal RNA sequences for phylogenetic analyses. Proc. Natl. Acad. Sci. USA 82:6955-6959.

18. Lo, S.-L., C. E. Montague, and E. L. Chang. 1989. Purification of glycerol dialkyl nonitol tetraether from Sulfolobus acidocaldarius. J. Lipid Res. 30: 944-949.

19. Marmur, J. 1961. A procedure for the isolation of deoxyribonucleic acid from microorganisms. J. Mol. Biol. 3:208-218.

20. Nishimura, M., H. Morii, and Y. Koga. 1987. Structure determination of a quartet of novel tetraether lipids from Methanobacterium thermoautotrophicum. J. Biochem. 101:1007-1015.

21. Olsen, G. J., N. R. Pace, M. Nuell, B. P. Kaine, R. Gupta, and C. R. Woese. 1985. Sequence of the 16S rRNA gene from thermoacidophilic archaebacterium Sulfolobus solfataricus and its evolutionary implications. J. Mol. Evol. 22:301-307.

22. Saitou, N., and M. Nei. 1987. The neighbor-joining method: a new method for reconstructing phylogenetic trees. Mol. Biol. Evol. 4:406-425.

23. Segerer, A., A. Neuner, J. K. Kristjansson, and K. O. Stetter. 1986. Acidianus infernus gen. nov., sp. nov., and Acidianus brierleyi comb. nov.: facultatively aerobic, extremely acidophilic, thermophilic, sulfer-metabolizing archaebacteria. Int. J. Syst. Bacteriol. 36:559-564.

24. Segerer, A., A. Trincone, M. Gahrtz, and K. O. Stetter. 1991. Stygiolobus azoricus gen. nov., sp. nov. represents a novel genus of anaerobic, extremely thermophilic archaebacteria of the order Sulfolobales. Int. J. Syst. Bacteriol. 41:495-501.

25. Stetter, K. O. 1989. Order III. Sulfolobales ord. nov., p. 2250-2253. In J. T. Staley, M. P. Bryant, N. Pfennig, and J. G. Holt (ed.), Bergey's manual of systematic bacteriology, vol. 3. The Williams \& Wilkins Co., Baltimore.

26. Sugai, A., R. Sakuma, I. Fukuda, N. Kurosawa, Y. H. Itoh, S. Ando, and T. Itoh. 1995. The structure of the core polyol of the ether lipids from Sulfolobus acidocaldarius. Lipids 30:339-344.

27. Suzuki, K., T. Kaneko, and K. Komagata. 1981. Deoxyribonucleic acid homologies among coryneform bacteria. Int. J. Syst. Bacteriol. 31:131-138.

28. Takayanagi, S., S. Morimura, H. Kusaoke, Y. Yokoyama, K. Kano, and M. Shioda. 1992. Chromosomal structure of the halophilic archaebacterium Halobacterium salinarium. J. Bacteriol. 174:7207-7216.

29. Woese, C. R., O. Kandler, and M. L. Wheelis. 1990. Towards a natural system of organisms: proposal for the domains Archaea, Bacteria and Eukarya. Proc. Natl. Acad. Sci. USA 87:4547-4579.

30. Zillig, W. 1993. Confusion in the assignments of Sulfolobus sequences to Sulfolobus species. Nucleic Acids Res. 22:5273.

31. Zillig, W., K. O. Stetter, S. Wunderl, W. Schulz, H. Priess, and I. Scholz. 1980. The Sulfolobus-"Caldariella" group: taxonomy on the bases of the structure of DNA-dependent RNA polymerases. Arch. Microbiol. 125:259269.

32. Zillig, W., S. Yeats, I. Holz, A. Boeck, M. Rettenberger, F. Gropp, and G. Simon. 1986. Desulfurolobus ambivalens, new genus new species, an autotrophic archaebacterium facultatively oxidizing or reducing sulfur. Syst. Appl. Microbiol. 8:197-209. 